\title{
EL LEASING PARA EQUIPO INFORMÁTICO EN EL ESTADO COSTARRICENSE: IMPLICACIONES Y EFECTOS TÉCNICO-ECONÓMICOS
}

\author{
ROLANDO BOLAÑOS GARITA \\ Universidad Estatal a Distancia, Costa Rica \\ rbolanos@uned.ac.cr
}

\section{RESUMEN}

El fenómeno del Leasing en el Sector Público costarricense, a pesar de ser reconocido desde varias perspectivas administrativistas, hasta ahora empieza a ser promovido por las instancias gubernamentales como aparente mecanismo para contener el gasto público, aún y cuando no se ha llevado a cabo una valoración integral sobre sus implicaciones. Engarzado con lo anterior, el presente aporte investigativo sobre dicho fenómeno es de naturaleza descriptiva con tintes exploratorios, y se espera que resulte de utilidad para todos aquellos involucrados en las decisiones gubernativas, al igual que a investigadores y estudiosos de la fenomenología propia de la Administración Pública.

PALABRAS CLAVE: ADMINISTRACIÓN PÚBLICA, LEASING, GASTO PÚBLICO.

\section{ABSTRACT}

Leasing in Costa Rica's public administration is just being promoted by the government as a mechanism to limit public spending, even when a complete assessment on its implications has not been carried out, yet. This article pretends to be useful for all those involved in government decisions, as well as researchers and students of this topic.

KEYWORDS: PUBLIC ADMINISTRATION, LEASING, PUBLIC SPENDING.

\section{INTRODUCCIÓN}

A raíz de nuestros estudios doctorales en la UNED, procedimos a llevar a cabo una breve investigación acerca de las implicaciones del Leasing en el Sector Público, considerando que anualmente el conglomerado de instituciones públicas que componen el Estado costarricense, incluyen en sus presupuestos sumas millonarias para la adquisición de equipo informático.

La razonabilidad de ello radica en que desde finales del siglo XX y ahora en el actual siglo XXI, se ha dado un aumento exponencial de los medios electrónicos y digitales para lograr una mejor interconexión entre usuarios de los servicios, mejorar los mecanismos de envío y resguardo de información, agilizar la toma de decisiones y el envío y procesamiento de datos, entre otros. El acercamiento de los servicios al público usuario, llámense matrícula universitaria, consultas registrales, solicitud de certificaciones, transferencias bancarias, por citar solo algunos, son posibles si se cuenta con el recurso computacional en cantidades y calidades adecuadas.

El empleo de recursos públicos para las contrataciones anteriores, fundamentalmente para la Administración Central, sufrirá un cambio a partir 
de 2012, ya que, según la línea establecida desde el Ministerio de Hacienda', las instituciones ya no cuentan con recursos para la compra de los equipos indicados, y es la Dirección General de Presupuesto Nacional la que informa que la metodología por emplear para el siguiente ejercicio económico será la activación de la figura del Leasing, como aparente mecanismo para la contención del gasto público.

No obstante lo anterior, a la fecha no se ha realizado ningún proceso investigativo ${ }^{2}$, que permita proveer de herramientas al Estado costarricense para determinar realmente si la figura del Leasing es realmente una alternativa factible desde una perspectiva económico-financiera y técnica, o si por el contrario deviene en un disparador del gasto público, esto en momentos en los que el país se debate sobre el tema de una reforma fiscal que venga, correlativamente, a sustentar el accionar de las instituciones del conglomerado estatal en rubros en los que más bien se desea generar austeridad.

Así, entonces, conviene investigar si la figura el Leasing es una herramienta administrativa eficaz para lograr el mejor desempeño de las instituciones públicas y si la figura como tal resulta acorde con las necesidades institucionales públicas, o más bien existen otras de mayor viabilidad económico-financiera y técnica, muy a pesar de la directriz girada por el Ministerio de Hacienda costarricense.

1. A través de la Directriz $\mathrm{H}-22$ y el Decreto Ejecutivo 36755-H.

2. Incluso el Banco Mundial y el Banco Interamericano de Desarrollo en el Informe Costa Rica: Desempeño de la Gestión de Finanzas Públicas 2010, en ningún momento aborda la temática del Leasing como opción para el mejor desempeño de gestión financiera y presupuestaria, lo que aumenta la necesidad de lograr un abordaje analítico sobre la misma.

\section{Naturaleza jurídica del Leasing}

Previo a profundizar en cualquier tipo de análisis, resulta primordial concretar en el sentido etimológico del Leasing, con el cual se busca esclarecer otra serie de particularidades, así como las consiguientes implicaciones para las organizaciones que buscan emplearlo.

El jurista José Leyva Saavedra detalla el concepto de Leasing de la siguiente manera:

En nuestra opinión, el Leasing es un contrato de financiamiento en virtud del cual una de las partes, la empresa de Leasing, se obliga a adquirir y luego dar en uso un bien de capital elegido, previamente, por la otra parte, la empresa usuaria, a cambio del pago de un canon como contraprestación por esta, durante un determinado plazo contractual, que generalmente coincide con la vida útil del bien, finalizado el cual, puede ejercer la opción de compra, pagando el valor residual pactado, prorrogar o firmar un nuevo contrato o, en su defecto, devolver el bien (Leyva, 2003, p.752).

Dependiendo de las implicaciones técnicas y jurídicas, el Leasing puede clasificarse principalmente: por su finalidad, por la naturaleza del bien y por su promoción.

\section{Por su finalidad}

Recurriendo en la mayoría de los casos nuevamente a Leyva Saavedra (2003, p. 757-762), el Leasing puede clasificarse de las siguientes formas:

\section{Leasing Operativo}

Es una modalidad contractual de comercialización por la cual una empresa, habitualmente fabricante o proveedora, denominada arrendadora, se obliga a ceder, durante un plazo determinado, el uso de un bien o bienes a otra em- 
presa, denominada arrendataria, a cambio de un pago periódico como contraprestación. Por lo general, estos contratos vienen acompañados de servicios como: mantenimiento, reparación, asistencia técnica, entre otros.

Algunos autores como Mesalles (2002), indican que usualmente esta modalidad no contiene una opción de compra, pero si la tuviere, sería por el valor comercial del activo (valor de mercado), por lo que en el criterio de Arias (2006) el arrendatario no adquiere ningún derecho porque no se considera que haya amortizado nada del precio total del activo. Conceptualmente, esta clase de arrendamiento está diseñada para que el arrendatario utilice el activo arrendado sin tener que comprarlo, permitiéndole así, renovar el activo por uno nuevo al finalizar el período original del contrato.

La línea anterior se ve respaldada por lo indicado en el artículo 2 del Decreto Ejecutivo 32876$\mathrm{H}$, denominado: "Medidas tendientes a evitar el abuso en detrimento del interés fiscal de la figura del Leasing", que señala:

Se considerará, para efectos de la Ley del Impuesto sobre la Renta, como contratos de "arrendamiento operativo" o "Leasing operativo", todos aquellos contratos de arrendamiento con opción de compra o renovación que califiquen en las definiciones a que se refiere el artículo 3 de este Decreto.

Según la línea de tratamiento fiscal establecida en el anterior "Reglamento para el Tratamiento Tributario de Arrendamientos Financieros y Operativos", Decreto Ejecutivo 30389-H, el arrendatario podía deducir como gasto del período las cuotas del arrendamiento canceladas en dicho período, y en su defecto no podía deducir monto alguno por concepto de depreciación del bien arrendado, en razón de que este es propiedad del arrendador.

\section{Leasing Financiero}

Según el último de los autores de referencia, este tipo de Leasing permite que el bien dado vaya poco a poco autofinanciándose, pues los montos periódicos pactados como contraprestación se pagan con los ingresos que generan el uso del bien.

No obstante lo anterior, esta modalidad se ha distinguido en el ambiente costarricense según Arias (2006), por cuanto "se plantea que al final del periodo establecido en el contrato, el activo arrendado pase a ser propiedad de la empresa que lo arrendó" (p.133).

En forma cónsona con lo anterior, Jinesta (1992, p.19) detalla que intervienen tres sujetos: a) fabricante o proveedor, b) dador (intermediario financiero) y c) tomador o usuario. Se distingue esta modalidad porque es practicada por sociedades especializadas con vocación financiera: invierten su capital en activos fijos, y ceden su uso y goce a terceros para obtener un beneficio.

\section{Leasing operativo en función financiera}

Una tercera figura que parece fusionar las dos anteriores es el Leasing operativo en función financiera, estipulado en el artículo 3 del Decreto Ejecutivo 32876-H citado en líneas precedentes, mismo que establece:

Se considerará, para efectos tributarios, dentro de la categoría de contratos de "arrendamiento operativo" o "Leasing operativo", aquellos en los que los arrendantes son entidades financieras o empresas dedicadas habitualmente al negocio de arrendamiento de activos con opción de compra o renovación, y que tengan un capital mínimo de quinientos mil dólares, moneda de los Estados Unidos de América, y en que los arrendatarios pueden ser cualquier persona física, jurídica, o ente colectivo sin personali- 
dad jurídica que tenga carácter de contribuyente autónomo de acuerdo con la Ley del Impuesto sobre la Renta, que requieran de financiación para sus actividades profesionales o empresariales. Se caracterizan porque, tras un período de arrendamiento, el arrendatario tiene derecho a adquirir el bien mediante el pago de una "opción de compra" previamente determinada al celebrarse el contrato.

Según la línea de tratamiento fiscal, tendrán la consideración de gasto deducible de la base imponible para efectos del impuesto sobre la renta del arrendatario: a) las cuotas del arrendamiento, b) la parte de las cuotas de arrendamiento pagadas, correspondiente a la recuperación del costo del bien, salvo en el caso de que el contrato tenga por objeto terrenos y otros activos no sujetos a depreciación.

El importe de la cantidad deducible de acuerdo con lo dispuesto en el inciso b) anterior, no podrá ser superior al resultado de aplicar al costo del bien el doble del porcentaje de depreciación que, por el método de línea recta, corresponda al bien, según lo previsto en el Anexo 2 del Reglamento a la Ley del Impuesto sobre la Renta.

\section{Operatividad del Leasing Ventajas para el sector público}

Las ventajas que Mesalles (2002, p. 215-217) presenta para el Sector Público son las siguientes:

I. En tanto el Leasing ayude a un mayor crecimiento de la producción nacional, la base impositiva sobre la cual se recaudan impuestos tenderá a aumentar, incrementando, a su vez, los ingresos para el fisco. Además, las inversiones hechas en activos por medio de arrendamiento usualmente pagan impuestos, generando un beneficio adicional para el Leasing.
II. El mecanismo de arrendamiento también puede ayudar a facilitar los procesos de compra de activos por parte de las instituciones públicas. Es más, con la figura del Leasing operativo, las instituciones no tienen que comprar los activos para poder aprovecharse de su uso. En una situación de déficit fiscal elevado, la compra de activos genera un aumento en las cifras del déficit en el mismo año de la compra, mientras que en el Leasing este costo se diluye a través del tiempo.

III. El arrendamiento le permite al Estado una renovación tecnológica más acelerada, sin tener que lidiar con el mercado secundario. Con todas las restricciones que usualmente tienen las instituciones públicas para vender activos, el Leasing les elimina una complicación más, amén de darle a especialistas en el mercado secundario el activo para que ellos lo negocien.

Para aclarar lo que comprendemos como déficit fiscal señalado en el punto II, recurrimos a la Contraloría General de la República al indicar:

El término recaudación se refiere a la cobranza de rentas públicas, y en general a la percepción de fondos públicos. El funcionario o empleado encargado de realizar esta función se denomina recaudador o perceptor de fondos públicos. En materia tributaria, la gestión recaudatoria consiste en el ejercicio de la función administrativa conducente a la realización de los créditos y derechos que constituyen el Haber del Estado y, en su caso, de los demás entes y órganos públicos. Dicha función tiene como finalidad específica la cobranza de los impuestos, contribuciones especiales, tasas, multas y otros ingresos que figuren en los presupuestos generales del Estado; de las cantidades que deben percibir las Entidades Locales, los Organismos Autónomos de la Administración del Estado y de- 
más entes públicos, salvo las excepciones establecidas por Ley (2004, p. 3).

Bajo ese prisma, el déficit fiscal no es otra cosa que el desbalance entre los ingresos corrientes percibidos con base en el Marco Normativo Tributario y los ingresos de capital incorporados en los presupuestos institucionales, los cuales se componen mayoritariamente de mecanismos de deuda (títulos de deuda o empréstitos internacionales).

Entre mayor sea el financiamiento del presupuesto público vía ingresos de capital, como consecuencia de mayores gastos institucionales dedicados en teoría a la atención de necesidades poblacionales, mayor será el desbalance y por ende el déficit, siendo que ahora la presión sobre las finanzas públicas incorpora otro componente aparte del gasto operativo de las instituciones, y es, el pago total de las deudas adquiridas (capital + intereses).

\section{RESULTADOS DE LA INVESTIGACIÓN}

\section{Consideraciones técnico-económicas}

Una parte esencial del trabajo investigativo según los objetivos propuestos, consistió en determinar las características técnicas del equipo de cómputo sujeto de Leasing, el cual, en la generalidad, ostenta prácticamente las mismas características en todas las instituciones públicas. Para ello, se revisaron Carteles de Contratación Administrativa tipo Leasing, promovidos entre 2006 y 2010 por instituciones como el Instituto Costarricense de Acueductos y Alcantarillados, y el Ministerio de Relaciones Exteriores y Culto.

Aunado a dichas características técnicas, debe hacerse mención a las condiciones cartelarias establecidas para las anteriores licitaciones, tales como: obligaciones del oferente, obligaciones del contratista, condiciones generales para ambas partes, metodología de evaluación de las ofertas (financiera y técnica), acuerdo de confidencialidad, entre otros. La observación de tales procesos licitatorios denota la necesidad de que los funcionarios públicos que promueven y gerencien estos actos administrativos, tengan un conocimiento bastante amplio al respecto, debiendo tener claridad sobre consideraciones de tipo técnico, legal, de contratación administrativa y presupuestario; de lo contrario, se exponen a situaciones $u$ ofertas que causen un perjuicio para la Administración. Resulta imprescindible que los analistas estatales salvaguarden los recursos públicos a través de requisitos y cláusulas contractuales claras, estableciendo incluso multas por incumplimientos; asimismo, se debe estar atento a la presentación de posibles ofertas ruinosas que no se ajusten a los requerimientos de equipo y que, por el contrario, generen un detrimento o incluso riesgos legales para el Estado.

La clave para concretar un proceso licitatorio exitoso en el Sector Público conlleva el conocimiento que sobre el objeto por adquirir tengan quienes promueven el concurso, tanto en lo anteriormente descrito, como incluso en aspectos de precios de mercado; en esta línea, un proveedor que presenta precios muy por debajo de sus competidores puede no estar claro en las condiciones establecidas por la Administración, y aún peor, podría, en su defecto, estar presentando equipo muy por debajo de los estándares de funcionamiento requerido, o bien, careciendo de una infraestructura o capacidad logística óptima para atender las necesidades de las instituciones públicas, no necesariamente al inicio de la contratación, pero sí durante el lapso que dure la relación comercial.

A partir del estudio de mercado llevado a cabo, se procedió a elaborar un análisis costo-beneficio, buscando hallar el punto de equilibrio económico que permita determinar si, incluidos todos los costos y gastos implícitos, resulta, según criterios económicos, de mayor beneficio para el 
Sector Público la compra de activos o el alquiler de equipo vía Leasing.

Primeramente, se ha determinado que la depreciación anual según lo establecido por el Ministerio de Hacienda es la que sigue:

$$
D t=\$ 1000-\$ 1 *=\$ 199
$$

5

* El valor residual de $\$ 1$, se establece siguiendo las instrucciones vertidas por la Contabilidad Nacional a la Dirección General de Administración de Bienes y Contratación Administrativa, ambas del Ministerio de Hacienda, según se expone en la Circular DGABCA-NP-1026-2007.

En esta misma línea, y tomando como referencia el valor de mercado más alto obtenido, con fundamento en la posibilidad de que en un proceso licitatorio las empresas participantes presenten al menos el monto mayor, lo que permite a la Administración salvaguardar su responsabilidad ante precios ruinosos, y sobre todo, no declarar infructuoso el proceso por falta de contenido económico. Se presenta en la siguiente tabla el detalle global de erogaciones para el caso de compra de equipo de cómputo.
En el caso de compra del equipo la misma incluye: hardware y software completo; no obstante, al tercer año se debe realizar una actualización del sistema operativo, paquete de oficina y antivirus.

Según la Tabla 1, aparte de la inversión inicial para la adquisición del equipo, se deben contemplar conceptos como seguros y renovación al tercer año del software. La depreciación acumulada, a pesar de verse reflejada, no constituye propiamente un elemento considerativo, pues la Administración Central no mantiene una contabilidad por partida doble, y dicha depreciación no es utilizable finalmente como escudo fiscal, aspecto que sí es de consideración en el sector privado.

Aunado a lo anterior, debe tenerse claridad de que, quien brinda el soporte de la instalación, así como el mantenimiento preventivo y correctivo es el propietario del equipo, lo que conlleva costos por este concepto que se traducen en horas hombres dedicadas a ello. Según las proyecciones realizadas, se tienen los siguientes dos posibles montos por este concepto:

TABLA 1

DETALLE DE EROGACIONES POR COMPRA DE EQUIPO DE CÓMPUTO

\begin{tabular}{|c|c|c|c|c|c|c|c|}
\hline \multicolumn{8}{|l|}{ Empresa Privada Promedio } \\
\hline Elementos de Costo total de propiedad & Año 0 & Año 1 & Año 2 & Año 3 & Año 4 & Año 5 & $\begin{array}{c}\text { Total x } \\
\text { elemento } \\
\text { costo }\end{array}$ \\
\hline 1.Costo de la Compra & $\$ 1895,00$ & & & & & & \\
\hline 2.Costo del Seguro & $\$ 80,00$ & $\$ 80,00$ & $\$ 80,00$ & $\$ 80,00$ & $\$ 80,00$ & $\$ 80,00$ & \\
\hline 3.Gasto por depreciación acumulada & & $-\$ 379,00$ & $-\$ 379,00$ & $-\$ 379,00$ & $-\$ 379,00$ & $-\$ 379,00$ & \\
\hline $\begin{array}{l}\text { 4. Costo de mantener diferentes generaciones de equipo que deben } \\
\text { interactuar y producir = Complejidad }\end{array}$ & & & & $\$ 70,00$ & & & \\
\hline Total por año: & $\$ 1975,00$ & $\$ 80,00$ & $\$ 80,00$ & $\$ 150,00$ & $\$ 80,00$ & $\$ 80,00$ & $\$ 2445,00$ \\
\hline Posible recuperación de la inversión por venta anticipada & & $\$ 1516,00$ & $\$ 1137,00$ & $\$ 758,00$ & $\$ 379,00$ & $\$ 1,00$ & \\
\hline
\end{tabular}

Fuente: elaboración propia, como referencia de un caso ficticio. 

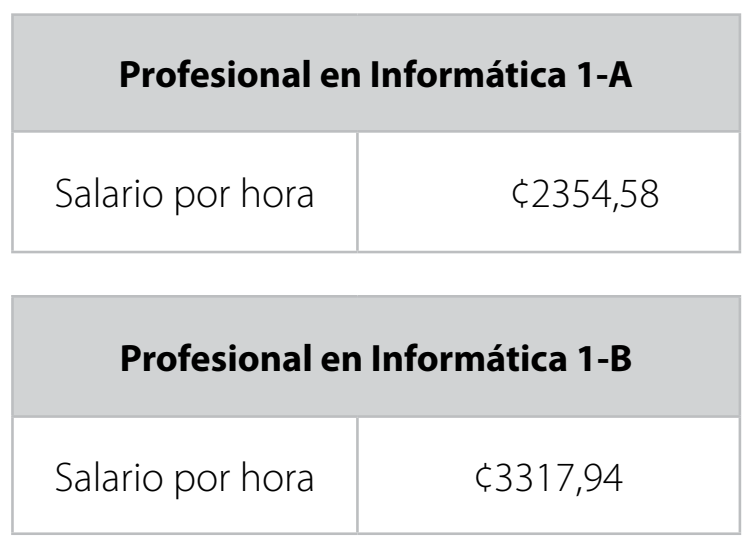

Nótese que el valor por hora-hombre para un funcionario público de nivel técnico o profesional, únicamente permite estimar el costo mínimo en que se incurría por razones de soporte técnico. Dicho soporte, de hecho, inicia desde la misma compra, ya que la instalación y las pruebas de funcionamiento deberán correr por parte de la institución adquiriente, al igual que las posibles situaciones como errores en el funcionamiento durante la vida útil del equipo, instalación de otros sistemas, pruebas de impresión, entre otros.

No obstante, y a pesar de no tenerse certeza de la posible cantidad de horas-hombre que se necesitarían para lograr el mejor funcionamiento del activo durante su vida útil, desde ahora puede inferirse que el pago de esos salarios es prácticamente un costo, y que bien podrá emplearse en otras acciones más estratégicas para la organización.

Ahora bien, si el objetivo fuera vender el bien para al menos recobrar el monto de la inversión inicial esto podría no cumplirse, ya que por efecto de la depreciación, a partir del año 1, ya el valor del bien está por debajo de la inversión inicial, aunado al hecho de que no puede obligarse a los posibles compradores a aceptar el precio propuesto una vez restada la depreciación, puesto que no es un valor de mercado y el estado y la obsolescencia tecnológica puede empujar hacia abajo el monto con que oferten los interesados en un posible remate.

El aspecto no es desdeñable, pues incluso para deshacerse de un activo obsoleto, la Administración Pública debe incurrir en una serie de procesos como: realizar un avalúo del activo para determinar el monto base del remate y llevar a cabo todos los pasos de un remate normado por la Ley de Contratación Administrativa 7494 y su Reglamento, desde la formulación del cartel y la recepción de las ofertas, hasta la adjudicación.

Todo ello conlleva costos implícitos traducidos en recursos públicos (técnicos, humanos y financieros) destinados a lograr deshacerse de la estación computacional.

TABLA 2

DETALLE DE EROGACIONES POR CONCEPTO DE LEASING

\begin{tabular}{|c|c|c|c|c|c|c|c|}
\hline Empresa Privada Promedio & & & & & & & \\
\hline Elementos de Costo total de propiedad & Año 0 & Año 1 & Año 2 & Año 3 & Año 4 & Año 5 & Total $\mathrm{x}$ elemento costo \\
\hline 1.Costo del Alquiler* & & $\$ 500,00$ & $\$ 500,00$ & $\$ 500,00$ & $\$ 500,00$ & $\$ 500,00$ & $\$ 2500,00$ \\
\hline Total por año: & & $\$ 500,00$ & $\$ 500,00$ & $\$ 500,00$ & $\$ 500,00$ & $\$ 500,00$ & $\$ 2500,00$ \\
\hline
\end{tabular}

* El alquiler incluye: sistema operativo completo, paquetes de oficina, antivirus corporativo, mantenimiento preventivo y correctivo al menos 3 veces por año (revisiones generales de hardware y software), seguro global (pérdida, robo, incendio), instalación y pruebas de funcionamiento, repuestos o reposición del activo en caso de mal funcionamiento, actualización al tercer año de hardware y software.

Fuente: elaboración propia, como referencia de un caso ficticio. 
En la Tabla 2 se presenta el detalle global de erogaciones para el caso de Leasing de equipo de cómputo.

Dentro del valor de los pagos mensuales, en el caso anterior se incluye: sistema operativo completo, paquetes de oficina, antivirus corporativo, mantenimiento preventivo al menos 3 veces por año (revisiones generales de hardware y software), seguro global (pérdida, robo, incendio), instalación y pruebas de funcionamiento, repuestos o reposición del activo en caso de mal funcionamiento, actualización al tercer año de hardware y software.

Igualmente, el soporte por mantenimiento preventivo correrá por cuenta del arrendante en razón de ser este el propietario del activo y no la institución pública arrendataria.
En este caso, y siguiendo lo dispuesto en el Decreto Ejecutivo 32876-H, las cuotas del arrendamiento tendrán, para efectos fiscales, la consideración de gasto deducible, aspecto que tampoco es de recibo para la Administración Central, ya que esta no mantiene una contabilidad por partida doble, tal y como se indicó en líneas precedentes.

Valga aclarar que lo correspondiente al pago de impuestos sí se encuentra implícito en el pago de cuotas de Leasing, esto ya que cuando el Estado compra un activo lo hace exento del impuesto sobre las ventas; en cambio, cuanto aplica el Leasing, el arrendante debe comprar el bien con impuesto incluido, dado que será de su propiedad y diluye su inversión en los pagos por arrendamiento.

La Tabla 3 siguiente presenta las diferencias genéricas entre el Leasing y la compra del equipo aplicables al Sector Público.

TABLA 3

\section{DIFERENCIAS GENÉRICAS ENTRE EL LEASING Y LA COMPRA DE EQUIPO}

\begin{tabular}{|l|l|l|}
\multicolumn{1}{|c|}{ FACTOR } & \multicolumn{1}{|c|}{ COMPRA DE EQUIPO } & LEASING DE EQUIPO \\
\hline Inversión inicial & Alta & No aplica \\
\hline Naturaleza técnico-jurídica & Compra y aumento patrimonial & Financiamiento sin aumento patrimonial \\
\hline Naturaleza contable & Gasto por depreciación & Gasto por arrendamiento \\
\hline Mantenimiento preventivo y correctivo & Responsabilidad de la institución pública & Responsabilidad del empresario privado \\
\hline Proceso de desecho & $\begin{array}{l}\text { Responsabilidad de la institución pública, debe ser bajo } \\
\text { criterios jurídicos y ambientales }\end{array}$ & Responsabilidad del empresario privado \\
\hline Pago de impuestos & $\begin{array}{l}\text { No se reconoce en razón de la exención de que goza el } \\
\text { Estado }\end{array}$ & Implícitos en las cuotas de Leasing \\
\hline
\end{tabular}

Fuente: elaboración propia. 
El Gráfico 1 permite ubicar visualmente el detalle de recursos económicos en que debe incurrir el Sector Público considerando ambas opciones. Dicho gráfico convierte a moneda nacional, los montos totales indicados en dólares correspondientes a la Tabla 1 y 2 anteriores. Podrá el lector notar cómo la última casilla de las ambas tablas arroja un monto total, el cual hemos convertido a moneda nacional habiendo utilizado un tipo de cambio del dólar con respecto al colón de ¿511,00; lo cual nos brinda un monto comparativo entre ambas modalidades para el tiempo que dure la relación comercial.

\section{GRÁFICO 1 \\ COMPARATIVO DE COSTOS TOTALES POR MODALIDAD, CONFORME LA VIDA ÚTIL DEL ACTIVO}

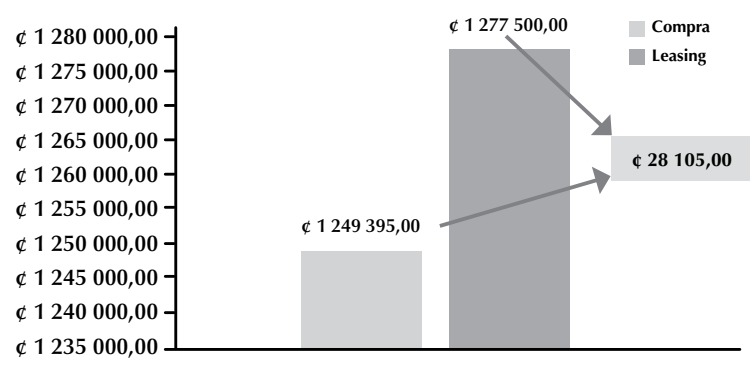

Fuente: elaboración propia

Tal y como se muestra en el gráfico 1, los pagos por concepto de Leasing se mantienen estables durante toda la vida del contrato, en cambio, la compra de equipo requiere de una alta inversión inicial, así como de una serie de erogaciones que, en teoría, deberían salvaguardar el estado de este y generarle un valor agregado. No obstante, han quedado excluidos otros costos que bien podrían considerarse asociados e ineludibles para con la compra del equipo, por ejemplo: horas hombre por tiempo de instalación y mantenimiento preventivo o correctivo. Todos estos deben realizarse en algún momento, pero variarán dependiendo de las condiciones del activo, pudiendo requerirse desde una hora o mucho más.

\section{Opinión de los sujetos ${ }^{3}$ de información acerca del Leasing}

A continuación, se presenta la información extraída a los sujetos de información establecidos en el anteproyecto de la investigación.

a) A un funcionario de la Dirección General de Administración de Bienes y Contratación Administrativa relacionado con los Convenios Marco promovidos para todas las instituciones usuarias del Sistema de Compras Públicas Compr@Red ${ }^{4}$.

Con base en la entrevista aplicada a dicho funcionario, se extrae que su relación con el tema del Leasing es limitada, teniendo la experiencia de sobre todo dos procesos de contratación administrativa en esa modalidad.

Dentro de los principales obstáculos que visualiza en el momento de tramitar el Leasing en el Sector Público menciona, en términos muy generales, lo relativo al pago de impuestos, ya que no se tiene claro aún el impacto de estos dentro de la modalidad Leasing, caso contrario con la compra de activos, ya que, cuando el Gobierno gestiona una compra, por ley se encuentra exento del pago de estos. Igualmente, otro de los obstáculos señalados es el conocimiento exacto de los costos asociados.

Por otra parte, los beneficios que vislumbra son: la posibilidad de cambiar el bien cuando termina el contrato, así como el ahorro en mantenimiento y conservación de los bienes; de lo ante-

3. A fin de mantener la objetividad de la investigación, se omiten los nombres de los sujetos de información aquí indicados.

4. Este sistema resulta obligatorio para todos los Ministerios de Gobierno y sus instancias adscritas según el artículo 3 del Decreto Ejecutivo 32717-H. Otras, a pesar de no verse sujetas a su uso, han decidido implementarlo, tal y como el caso de la Municipalidad de San José, el Tribunal Supremo de Elecciones y la UNED. 
rior se extrae que sí recomienda el Leasing como una opción viable para el Gobierno.

En el momento de consultarle sobre aspectos como: el precio ofertado por los proveedores, la garantía de estos para con el equipo y el factor depreciación, la respuestas brindadas fueron escuetas, limitándose a indicar que estos son aspectos sumamente importantes para decidirse sobre la aplicación o no del Leasing, o bien que la depreciación es importante exclusivamente como "señal de control de activos". Las anteriores respuestas permiten entrever un conocimiento limitado sobre la figura analizada, sobre todo en los elementos señalados, los cuales se consideran más que importantes, decisores para determinar finalmente su activación en el Sector Público.

b) Al Gerente General de una empresa que cuenta con más de 10 años de estar en el mercado costarricense ofreciendo soluciones de Leasing para organizaciones públicas y privadas.

En estos 10 años de actividad económica, han tramitado alrededor de 10 contratos con diferentes instituciones públicas. El hecho de que el Ministerio de Hacienda haya promovido la figura del Leasing, lo relaciona con la actual carencia de recursos del Gobierno (Flujo de Caja limitado o muy comprometido), y consiguientemente, esta le traería beneficios, al diluirse los pagos a través del tiempo, en contraposición con la aparente imposibilidad de sufragar una gran inversión en un solo tracto.

Como parte de las limitaciones para la activación de la figura, menciona principalmente, la falta de experiencia en el tema por parte de los funcionarios involucrados, así como la carencia de una visión integral, ya que, según su experiencia, los funcionarios públicos focalizan su atención en tres elementos: precio del activo, tasa de interés de los pagos mensuales y plazo de los contratos, dejando de ver otros que resultan valiosos de considerar, como el ahorro en costos asociados en el caso de compra de activos.

De hecho, considera que los conocimientos que ostentan los funcionarios públicos sobre la figura es variopinto, pero definitivamente existen grandes vacíos a nivel de impacto y beneficios financieros.

\section{CONCLUSIONES}

1. El fenómeno del Leasing es conocido y operado a nivel costarricense de forma teórico-jurídica y teórico-económica, según pudimos acceder y presentar las citas bibliográficas de los trabajos de Ernesto Jinesta Lobo y Luis Mesalles Jorba.

2. De manera más específica, a través del anterior Reglamento para el Tratamiento Tributario de Arrendamientos Financieros y Operativos, Decreto Ejecutivo 30389-H, se establecían, por primera vez, las regulaciones para con los Contratos de Leasing en las modalidades de arrendamiento operativo y financiero, contándose, a partir de ese acto, con un marco regulatorio que permitía consolidar el abordaje jurídico y contable que podía dársele al fenómeno en Costa Rica.

El anterior reglamento contenía explicaciones sobre las figuras propias del Leasing que permitían una mejor orientación sobre el tratamiento del fenómeno, tanto en aspectos jurídico-contractuales, como contablefinancieros, claridad que se perdió al derogarse dicha norma técnica. No obstante, a la fecha, el Leasing se sigue empleando de forma cada vez más consolidada, según se desprende de lo establecido por el Ministerio de Hacienda en las "Directrices Generales de Política Presupuestaria para las Entidades Públicas, Ministerios y demás Órganos según corresponda, cubiertos por el ámbito de la Au- 
toridad Presupuestaria, para el año 2011 y sus reformas."

En la última de las reformas a tales directrices a través del Decreto Ejecutivo 36755-H, se exhorta a las entidades públicas, Ministerios y demás órganos públicos que requieran adquirir equipo de cómputo, a realizar tal adquisición a través del Leasing operativo, exhortación que se vislumbra en el Considerando 4 del Decreto, al señalar:

Que en nuestra legislación existen mecanismos de contratación de bienes y servicios, que pueden ser utilizados por la Administración Pública, y que contribuyen con el uso racional de los recursos.

Dicho considerando es hasta cierto punto fáctico, por cuanto, según nuestro criterio analítico, el anterior Decreto Ejecutivo 30389-H tal y como se indica en líneas superiores, sí permitía contar con un mejor marco orientador en materia jurídica y contable para el fenómeno del Leasing.

3. Las características técnicas, legales, presupuestarias e incluso operativas que rodean la figura del Leasing en Costa Rica, deben ineludiblemente ser conocidas por todos aquellos funcionarios y analistas relacionados con su operacionalización, tanto en sus etapas de activación, evaluación financiera y presupuestaria, como en su funcionamiento y la consiguiente evaluación contractual.

Según pudo determinarse a partir de la entrevista realizada al funcionario de la Dirección General de Administración de Bienes y Contratación Administrativa del Ministerio de Hacienda, las implicaciones de orden técnico, jurídico y contable del Leasing en el Sector Público no están del todo claras; aún más, dicha instancia no ha llevado a cabo un análisis de costo-beneficio que arroje luz sobre las bondades económico-presu- puestarias y de valor agregado del Leasing en comparación con la compra de equipo informático.

Dicho desconocimiento resulta paradójico, ya que no tiene sentido que el Ente Rector del Sistema de Administración Financiera según la Ley de Administración Financiera de la República y Presupuestos Públicos 8131, entiéndase Ministerio de Hacienda, promueva una figura contractual como contenedor del gasto público, sin que una de sus instancias haya realizado un análisis como el aquí desarrollado.

Lo anterior nos lleva a considerar que la Directriz H-22 y el Decreto 36755-H, las cuales cobijan a todas las instituciones de la Administración Central, así como aquellas descentralizadas que están bajo el alero de la Autoridad Presupuestaria, se emitieron sin sustento técnico-económico, lo cual deviene en una actitud inadecuada para con el óptimo manejo de la Hacienda Pública.

4. Por otra parte, según el Gerente de una empresa relacionada con el Leasing, los funcionarios públicos que han estado interesados en la figura del Leasing aún presentan falencias de conocimiento sobre esta figura, por ejemplo, al enfocar su atención en tres elementos como: precio del activo, tasa de interés de los pagos mensuales y plazo de los contratos, desatendiendo otros como el ahorro en costos asociados en el caso de compra de activos. Dichas falencias pueden ocasionar que la Directriz $\mathrm{H}-22$ y el Decreto $36755-\mathrm{H}$, no logren operacionalizarse en tiempo y forma adecuados, generando, por el contrario, incidencias negativas para las instituciones públicas, tales como: presentación de precios ruinosos por parte de proveedores, contrataciones públicas infructuosas, vacíos contractuales para la protección y salvaguarda de los recursos públi- 
cos, subejecuciones presupuestarias, entre otras.

Así, se procedió a validar la hipótesis propuesta, en el sentido de que la figura del Leasing conlleva el manejo de elementos técnicos, legales, operativos y financieros por parte de las instituciones públicas, los cuales son mayormente desconocidos por estas, lo que puede incidir negativamente en su gestión operativa y financiera.

5. De acuerdo con las proyecciones económicas realizadas para determinar los compromisos presupuestarios en que tiene que incurrir el Estado, tanto si opta por comprar equipo informático, como si opta por el financiamiento a través del Leasing para adquirir dicho equipo, tal y como se pudo valorar a través del Gráfico 1, se logra determinar que el Leasing sí resulta factible para lograr una contención en el gasto público, por cuanto la erogación total de recursos en que debe incurrirse durante el periodo de vida útil del activo, es hasta cierto punto menor en comparación con la compra de este, siempre y cuando los costos asociados como mantenimiento y soporte así lo determinen. De igual manera, las ventajas de valor agregado son también notorias en comparación con la compra del equipo, ya que al arrendarlo se ven incluidos elementos como: mantenimiento preventivo, repuestos o reposición del activo en caso de mal funcionamiento, disposición de este al término de su vida útil, antivirus, seguro global, pruebas de funcionamiento, actualizaciones, e incluso, el pago de impuestos.

6. En caso de optarse por la compra del equipo y su posterior venta mediante Remate, económicamente la Administración nunca recobraría el monto total de la inversión inicial, en razón del efecto que tiene la depreciación en el monto mínimo que podría es- tablecerse en la base del Remate. Aún más, dicho monto base no necesariamente debe ser respetado por quienes participen en el proceso, ya que por criterio de obsolescencia tecnológica bien podrían ofrecer menos, e incluso, no participar, con el consiguiente agravante de que la institución se quedaría con el equipo sin recuperar la inversión inicial, y con la responsabilidad de deshacerse del mismo siguiendo parámetros normativos y ambientales, proceso que genera un desgaste de recursos, ya que deben desviarse profesionales por un lapso no identificado aún, para lograr concluir con el desecho ya indicado, cuando más bien podrían atender otras acciones más estratégicas y de impacto institucional.

Para afincarnos en las dos anteriores conclusiones, echamos mano al esquema teórico provisto por Mesalles (2002), al indicar este que en una situación de déficit fiscal elevado la compra de activos genera un aumento en las cifras del déficit en el mismo año de la compra, mientras que en el caso de Leasing este costo se diluye a través del tiempo; bajo esa misma inteligencia, el arrendamiento le permite al Estado una renovación tecnológica más acelerada, sin tener que lidiar con el mercado secundario. Considérense también todas las restricciones que usualmente tienen las instituciones públicas para vender activos, por lo que el Leasing les elimina una complicación más, además de darle a especialistas en el mercado secundario el activo para que ellos lo negocien.

7. Resulta inexorable reconsiderar lo pertinente al mantenimiento correctivo del equipo en caso de mal uso o negligencia comprobada del funcionario público que lo tiene asignado. Nuestra recomendación al respecto, al no ser el equipo parte del erario público, es que se formalice una cláusula contractual en la cual el arrendante y el arrendatario 
pacten que este último se encargará de brindar el mantenimiento correctivo total bajo sus propios medios (técnicos, talleres y(o) repuestos), asegurando la rápida vuelta al funcionamiento del activo, pero generándole un cobro a la Administración si es que mediante procedimiento administrativo llevado a cabo según lo estipulado en el Libro Segundo de la Ley General de la Administración Pública 6227, se logra determinar la responsabilidad de quien funja como encargado del equipo.

Posterior al pago al arrendatario, la Administración deberá recobrar íntegramente los montos en que ha incurrido por la reparación, asentada en lo establecido en el artículo 203 y siguientes de la Ley 6227.

\section{RECOMENDACIONES}

1. Se recomienda al Ministerio de Hacienda de Costa Rica iniciar un proceso de sensibilización y capacitación dirigido al personal de la Dirección General de Administración de Bienes y Contratación Administrativa, con el objetivo de que logren ostentar un conocimiento tácito sobre las implicaciones y efectos técnico-económicos del fenómeno del Leasing dentro del Sector Público, ya que no solo están en posición de normar y guiar la serie de contrataciones públicas que sobre este se logren llevar a cabo individualmente a través de Compr@Red, sino de activar dicha figura dentro de un Convenio Marco que cobije a todas las instituciones que emplean dicho sistema.

2. Se recomienda al Ministerio de Hacienda de Costa Rica mantener y promover el uso de la figura del Leasing Operativo en función financiera, en todas las instituciones públicas cubiertas bajo el ámbito de la Autoridad Presupuestaria, por cuanto se ha logrado determinar su conveniencia técnica y eco- nómica en momentos en los que el país enfrenta un déficit fiscal.

3. Se recomienda al Ministerio de Hacienda de Costa Rica realizar una valoración integral de la normativa técnica que regula la aplicación del Leasing a nivel costarricense, prestando especial atención al anterior Reglamento para el Tratamiento Tributario de Arrendamientos Financieros y Operativos, Decreto Ejecutivo 30389-H no vigente en la actualidad, pero que consideramos explicitaba de mejor forma herramientas técnicoconceptuales de gran valía para normar el fenómeno del Leasing, tanto en materia jurídica, como contable y fiscal.

4. Se recomienda a las instancias públicas interesadas en promover contrataciones administrativas de naturaleza Leasing, la inclusión de la cláusula contractual detallada en el punto 7 anterior, con el objetivo de que puedan tanto lograr la agilidad en la recuperación del equipo en caso de daño, como la salvaguarda de los recursos públicos por motivo de negligencia comprobada de uno de sus agentes.

\section{REFERENCIAS}

Arias, M. (2006). Arrendamiento de Tecnología de Información. Revista de las Sedes Regionales UCR, 7 (12), 127-139.

Banco Mundial/Banco Interamericano de Desarrollo. (2010). Costa Rica: Informe Final de Desempeño de Finanzas Públicas. Washington: BM/BID.

Contabilidad Nacional del Ministerio de Hacienda. (2009). Directriz CN-001-2009 sobre Valoración, Revaluación, Depreciación de Propiedad Planta y Equipo. San José, Costa Rica, Mimeografiado.

Contraloría General de la República. (2012). Normas Técnicas sobre Presupuesto Público N-1-2012-DC-DFOE. San José: Contraloría General.

Contraloría General de la República. (2010). Informe sobre los resultados del estudio efectuado en el Ministerio de Hacienda, relacionado con la aplicación del régimen san- 
cionador por delitos tributarios. DFOE-SAF-IF-05-2010. San José: Contraloría General.

Dirección General de Administración de Bienes y Contratación Administrativa del Ministerio de Hacienda. (2007). Circular enviada a todos los encargados de bienes institucionales de la Administración Central e instituciones adscritas DGABCA-NP-1026-2007. San José, Costa Rica, Mimeografiado.

Jinesta, E. (1992). El contrato de Leasing financiero. Revista Judicial, 27 (55), 15-25.

Leyva, J. (2003). El Leasing y su configuración jurídica. Revista Vniversitas, 16, 743-789.

Lucke, R. (2008). Leasing: 44\% de crecimiento en un año. Revista Actualidad Económica. Recuperado el 04/10/2011 de http://www.actualidad-e.com/main.php?action=\& artid=1549\&catid=375\&template=art_list.tpl

Mesalles, L. (2002). El Leasing en Costa Rica. En: López, Grettel y Obando, Juan C. (Editores) Ensayos en honor de Claudio González Vega. pp. 213-232. San José: Academia de Centroamérica

Ministerio de Hacienda. (2011). Directrices Generales de Política Presupuestaria para las Entidades Públicas, Ministerios y demás Órganos según corresponda, cubiertos por el ámbito de la Autoridad Presupuestaria, para el año 2011 y sus reformas, Decreto Ejecutivo 36755-H. Recuperado el 07/10/2011 de http://www.pgr.go.cr/scij/ Busqueda/Normativa/Normas/nrm_repartidor.asp?p aram $1=$ NRTC\&nValor $1=1 \&$ nValor $2=71049 \&$ nValor $3=8$ $6063 \&$ strTipM=TC
Ministerio de Hacienda (2006). Medidas tendientes a evitar el abuso en detrimento del interés fiscal de la figura del Leasing, Decreto Ejecutivo 32876-H. Recuperado el 10/10/2011 de http://www.pgr.go.cr/scij/Busqueda/ Normativa/Normas/nrm_repartidor.asp?param 1=NR TC\&nValor1 $=1 \&$ nValor2=56429\&nValor3 $=61855 \&$ strTi $\mathrm{pM}=\mathrm{TC}$

Ministerio de Hacienda (2005). Reglamento para la Utilización del Sistema de Compras Gubernamentales Compra RED, Decreto Ejecutivo 32717-H. Recuperado el 01/02/2008 de http://www.pgr.go.cr/scij/Busqueda/ Normativa/Normas/nrm_repartidor.asp?param1=NR M\&nValor $1=1 \&$ nValor2 $=55729 \&$ nValor3 $=61056 \&$ strTi $\mathrm{pM}=\mathrm{FN}$

Ministerio de Hacienda (2002). Reglamento para el Tratamiento Tributario de Arrendamientos Financieros y Operativos, Decreto Ejecutivo 30389-H. Recuperado el 10/10/2011 de http://www.pgr.go.cr/scij/Busqueda/ Normativa/Normas/nrm_repartidor.asp?param1=NR M\&nValor1=1\&nValor2=48511\&nValor3=51690\&strTi $\mathrm{pM}=\mathrm{FN}$

Rodríguez, L. (2011). El equilibrio económico en los contratos administrativos. Revista de la Facultad de Derecho, $66,55-87$.

Recibido: 16-01-2012

Aceptado: 14-03-2012 